\title{
Optimizing the use of prescription drugs in Canada through the Common Drug Review
}

\author{
Mike Tierney BScPhm MSc, Braden Manns MD MSc, with the Members of the Canadian Expert Drug \\ Advisory Committee
}

$\infty \quad$ See related article page 428

A lthough pharmaceuticals have the ability to improve health outcomes, they are the fastest growing component of Canadian health care expenditures, with costs escalating at a rate of about $11 \%$ per year. ${ }^{1}$ In 2002 , federal, provincial and territorial ministers of health, who were concerned with the notable differences in coverage of prescription medications within their formularies and with the significant duplication of effort in reviewing new medicines, established the Common Drug Review process of the Canadian Agency for Drugs and Technologies in Health. The Common Drug Review is a single, national process to provide rigorous reviews and recommendations for formulary listing of new drugs to the 18 participating publicly funded drug plans. In this commentary we describe the Common Drug Review process and how it contributes to effective decision-making within public drug plans, and address criticisms of the program.

\section{Consideration of cost-effectiveness}

Drug formularies and policies support appropriate prescribing and optimize prescription drug use. If health care budgets were unlimited, information regarding whether a drug was safe and effective compared with existing therapies would be sufficient to ensure formulary listing. However, because health care funding is limited, new drugs should be added to a formulary only after an assessment of their cost-effectiveness.

Cost-effectiveness analysis includes simultaneous assessments of the impact of drugs on clinical outcomes and health care costs. The goal is to identify and fund treatments that maximize health to the greatest extent possible within the available budget. ${ }^{2}$ By analyzing the cost-effectiveness of new medications as part of its review process, the Common Drug Review acknowledges that health care budgets are limited and that funding a new medication may mean foregoing other effective interventions for patients.

\section{Review of new drugs in Canada}

It is important to clarify the roles of Health Canada, the Patented Medicines Prices Review Board and the Common Drug Review (Table I and Figure I), all 3 of which operate independently of one another and have different mandates and reporting relationships.

Health Canada ensures that marketed drugs in Canada meet standards for efficacy, safety and quality of manufactur-

\section{Key points of the article}

- Although pharmaceuticals have the ability to improve health outcomes, they are the fastest growing component of Canadian health care expenditures.

- By analyzing the cost-effectiveness of new medications as part of its review process, the Common Drug Review of the Canadian Agency for Drugs and Technologies in Health acknowledges that health care budgets are limited and that funding a new medication may mean foregoing other effective therapies.

- As part of the Common Drug Review process, the Canadian Expert Drug Advisory Committee makes recommendations for formulary listings to participating drug plans based on an assessment of the medications' effectiveness, safety and cost-effectiveness compared with existing therapies.

- Although drug plans are not required to follow the committee's recommendations, they are in agreement with the recommendations about $90 \%$ of the time.

ing. Although Health Canada approval enables a drug to be sold in Canada, its approval process does not consider the relative benefits, safety and cost-effectiveness of a new drug in relation to existing therapies.

The Patented Medicines Prices Review Board is a federal, independent, quasi-judicial body that ensures that the prices manufacturers charge for patented medicines in Canada are not excessive. It also ensures that the prices of "breakthrough" drugs do not exceed the median prices charged for the same drugs in other specified industrialized countries. The board is not mandated to consider whether the product provides reasonable value for the money.

The Common Drug Review is a process in which pharmaceutical manufacturers submit clinical information and pharmacoeconomic evaluations of new drugs that they wish to have reviewed for listing on the formularies of participating drug plans. A review team - comprising internally and externally contracted epidemiologists, pharmacists, physicians, health economists, a librarian and at least one physician with expertise in the relevant clinical area - prepares a clinical review, including a systematic review of all relevant published and un-

Mike Tierney is Vice-president, Common Drug Review, Canadian Agency for Drugs and Technologies in Health, Ottawa, Ont. Braden Manns is Chair, Canadian Expert Drug Advisory Committee, Canadian Agency for Drugs and Technologies in Health, Ottawa, Ont. 
published randomized controlled trials, and assesses and critiques the manufacturer's pharmacoeconomic evaluation.

The review team then prepares a report for the Canadian Expert Drug Advisory Committee. The committee assesses the medications' effectiveness, safety and cost-effectiveness compared with existing therapies and, on the basis of the assessment, makes a positive or negative recommendation for formulary listing to participating drug plans. The committee is composed of $\mathrm{I} 2$ members and a chair and generally includes physicians, pharmacists, pharmacologists and other health care professionals with expertise in clinical trial methodology, health technology assessment, drug policy or health economics. It also includes 2 public representatives who participate as full voting members. Committee terms of reference, member profiles and conflict-of-interest disclosures are available on the Canadian Agency for Drugs and Technologies in Health website (www.cadth.ca).

Although drugs often fail to be cost-effective due to their high prices, the Common Drug Review does not have the mandate to negotiate prices.

Once the Canadian Expert Drug Advisory Committee issues a recommendation, drug plans decide whether to list the drug on their formularies. Participating drug plans are not required to follow the committee's positive recommendations, because they also must consider their own health care priorities, available resources and the precedence of previous formulary decisions. Nonetheless, drug plan decisions are in agreement with the committee's recommendations about $90 \%$ of the time. ${ }^{3}$
The entire review process, from submission to recommendation, is completed within 4-6 months (Table I). The time from Health Canada's approval of a new drug to its listing on drug plan formularies has essentially gone unchanged when compared with the timeframe before the implementation of the Common Drug Review (47I v. 479 days), which indicates that the Common Drug Review has not delayed the coverage of new drugs. ${ }^{4}$

\section{Comparison with international drug approval processes}

Centralized drug review processes for the purpose of public reimbursement have become increasingly popular internationally in order to promote rational decision-making in the face of limited resources. In this regard, Canada's Common Drug Review program compares favourably with similar processes in the United Kingdom, Australia and New Zealand. ${ }^{5}$

\section{Information crucial to the Common Drug Review process}

The Canadian Expert Drug Advisory Committee, in its assessment of drug effectiveness, generally considers only evidence from randomized controlled trials because these types of studies represent the highest form of evidence

Table 1: Overview of the roles of Health Canada, the Patented Medicines Prices Review Board and the Common Drug Review of the Canadian Agency for Drugs and Technologies in Health in reviewing new drugs in Canada

\begin{tabular}{|c|c|c|c|}
\hline Role & \multicolumn{3}{|c|}{ Reviewing organization } \\
\hline Mandate & $\begin{array}{l}\text { Ensures that marketed drugs in } \\
\text { Canada meet standards for } \\
\text { efficacy, safety and } \\
\text { manufacturing quality }\end{array}$ & $\begin{array}{l}\text { Ensures that the prices charged } \\
\text { for patented medicines are not } \\
\text { excessive }\end{array}$ & $\begin{array}{l}\text { Considers evidence regarding } \\
\text { clinical effectiveness and cost- } \\
\text { effectiveness of new drugs in } \\
\text { comparison to existing therapies }\end{array}$ \\
\hline Conducts systematic reviews & No & No & Yes \\
\hline Considers unpublished trials & Yes & No & Yes \\
\hline $\begin{array}{l}\text { Evaluates new drugs in } \\
\text { relation to existing therapies }\end{array}$ & No & Yes & Yes \\
\hline $\begin{array}{l}\text { Public input and access to } \\
\text { deliberation process }\end{array}$ & $\begin{array}{l}\text { Summary basis of decision } \\
\text { published for drugs that have } \\
\text { been granted market } \\
\text { authorization }\end{array}$ & $\begin{array}{l}\text { Public hearings held to } \\
\text { determine whether price is } \\
\text { excessive }\end{array}$ & $\begin{array}{l}\text { Canadian Expert Drug Advisory } \\
\text { Committee includes } 2 \text { public } \\
\text { members; committee } \\
\text { recommendations and reasons } \\
\text { for recommendation are } \\
\text { published online }\end{array}$ \\
\hline
\end{tabular}

*Varies by product and year of reporting. 
when assessing the effectiveness of new drugs. Specifically, the committee focuses on randomized controlled trials that use clinical outcomes, such as mortality, the occurrence of an adverse clinical event (e.g., myocardial infarction, stroke), or a valid assessment of patient quality of life.$^{6} \mathrm{Un}$ fortunately, studies of new drugs all too often focus on nonclinical outcomes such as surrogate markers or clinical correlates. A valid surrogate marker is a laboratory measurement or physical sign that can be used as a reliable substitute for a clinical outcome (e.g., reduction in blood pressure for reducing stroke). ${ }^{7}$ A clinical correlate is associated with disease activity but often does not predict clinically meaningful change in response to an intervention (e.g., fever in septicemia). ${ }^{8}$

The use of nonclinical outcomes, particularly those that are not known to be valid surrogates, represents a particularly difficult challenge for the committee. Without proof of clinically meaningful benefit, it is difficult, if not impos- sible, to determine whether a new drug provides good value for the money.

\section{Addressing criticisms of the Common Drug Review}

The Common Drug Review program has been the subject of much attention and criticism, particularly from pharmaceutical manufacturers and industry associations but also, on occasion, from patient and professional groups. ${ }^{9}$ The following addresses some of these criticisms.

There has been criticism from the pharmaceutical industry and patient groups that the Common Drug Review process is not transparent. Before implementation of the Common Drug Review, the provinces did not provide an opportunity for manufacturers to comment on drug reviews, and detailed reasons behind drug plan decisions for formulary listings

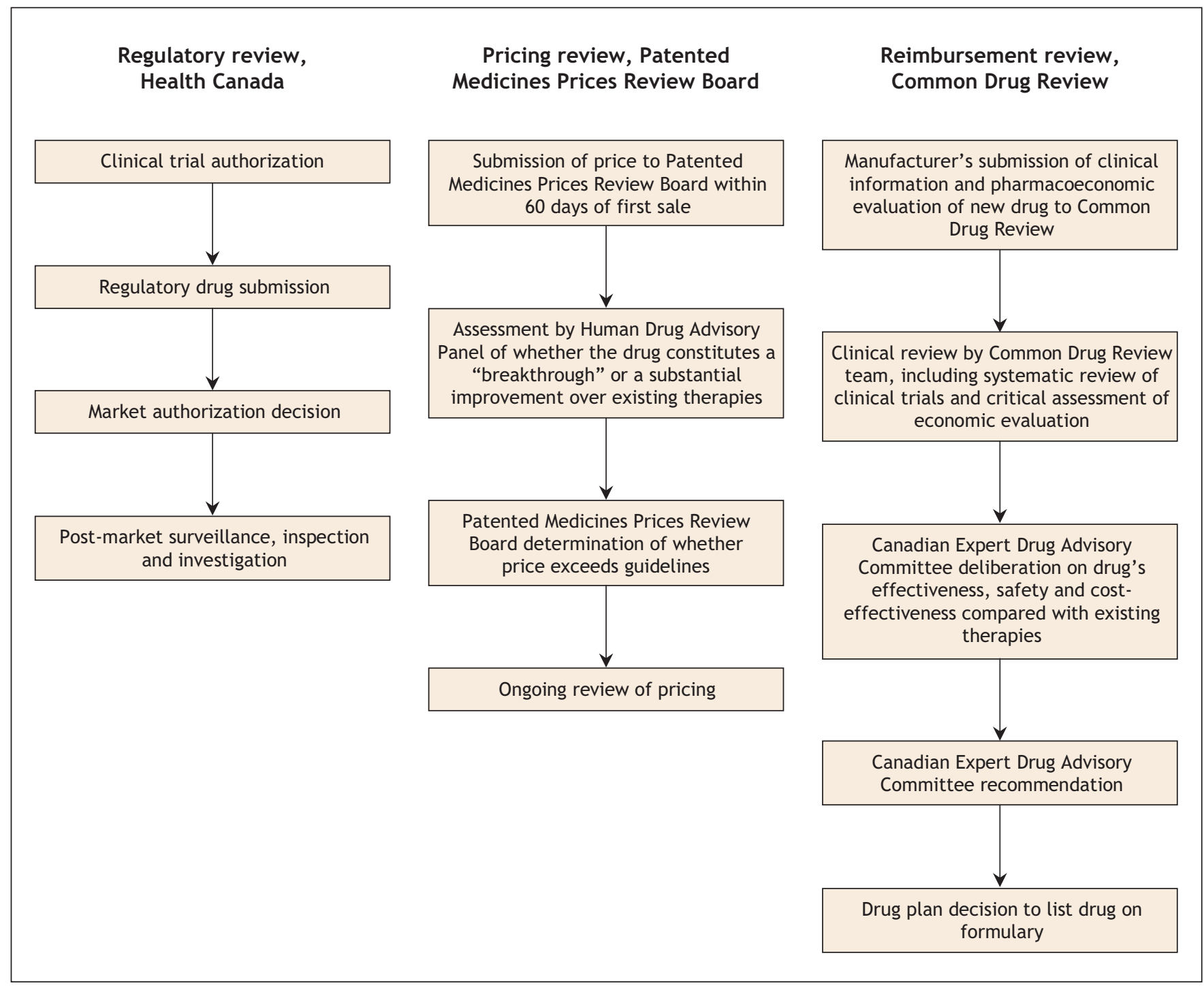

Figure 1: Summary of the review processes of Health Canada, the Patented Medicines Prices Review Board and the Common Drug Review of the Canadian Agency for Drugs and Technologies in Health when reviewing new drugs in Canada. 
were not available publicly. The Common Drug Review now allows manufacturers to review and provide feedback on all clinical and economic reports before the reports are submitted to the Canadian Expert Drug Advisory Committee for consideration. Furthermore, the status of all submissions and the committee's detailed recommendations and reasons for the recommendations are posted on the Canadian Agency for Drugs and Technologies in Health website (www.cadth.ca).

To improve transparency further, the Canadian Agency for Drugs and Technologies in Health appointed 2 public representatives to the Canadian Expert Drug Advisory Committee in 2006 and, in the coming year, plans to publish a plainlanguage version of the committee's recommendations, a summary of drug review discussions from the committee's meetings, and overviews of the Common Drug Review clinical and economic reviews.

A second criticism is that the Common Drug Review's conflict-of-interest guidelines exclude many experts. However, the process in fact includes clinical experts on all drug reviews. The conflict-of-interest guidelines ensure that all participants in the process disclose all potential conflicts with pharmaceutical manufacturers. The purpose of identifying people with close ties to the pharmaceutical industry is imperative to manage the real, potential or perceived conflict of all participants in the Common Drug Review process. Expert participants are not automatically excluded from the process if they have connections to the pharmaceutical industry, but their disclosures are considered carefully. The conflict-ofinterest guidelines for the Common Drug Review are posted on the Canadian Agency for Drugs and Technologies in Health website (www.cadth.ca).

Third, there has been criticism that the Common Drug Review approves fewer drugs than international approval processes. For example, a study commissioned by Canada's Research Based Pharmaceutical Companies (Rx\&D) reported that the Common Drug Review recommended listing $52 \%$ of the first 50 drugs reviewed and that this approval rate was significantly lower than the rate in many other countries. ${ }^{10}$ In fact, the study shows that this approval rate is in the midrange of that in other countries for the same drugs: New Zealand ${ }_{2} \%$, Australia 32\%, France $58 \%$, United Kingdom $76 \%$, Switzerland $80 \%$ and Sweden $82 \%$.

Finally, there is a misconception that the Common Drug Review only controls cost and does not recognize innovative drugs. In fact, drugs that have received a positive listing recommendation from the Canadian Expert Drug Advisory Committee include important new therapies for HIV infection, cancer, autoimmune disorders and pulmonary artery hypertension. When expensive drugs for rare diseases (arbitrarily defined as a drug for the treatment of a condition in fewer than 500 Canadians at a cost more than $\$ 100$ ooo per patient per year) are excluded, the median annual cost per patient of drugs recommended for listing by the committee in its first 3 years (\$12 045) was slightly higher than that of rejected drugs $(\$ 8830)$. This difference suggests that the Common Drug Review process recognizes that expensive drugs can still be cost-effective.

In summary, in its first 3 years, the Common Drug Review has recommended formulary listing of 29 of 55 new drugs and has met aggressive review timelines. Furthermore, participating drug plans have consistently followed the Canadian Expert Drug Advisory Committee's recommendations. Although the pharmaceutical industry has criticized the Common Drug Review program, it is important to recognize that the intent of the program is to serve the Canadian public by recommending drugs that have been demonstrated to improve health outcomes and are affordable to the Canadian health care system. The continued growth and evolution of the Common Drug Review program will help ensure the sustainability of publicly funded health care within Canada, which has been consistently rated as an important goal by Canadians.

\section{This article has been peer reviewed.}

Competing interests: None declared.

Contributors: Both authors contributed substantially to the content of the manuscript, drafted the article and revised it critically for intellectual content, and have reviewed and given their final approval of the version to be published.

\section{REFERENCES}

I. Canadian Institute for Health Information. Drug expenditure in Canada, 1985 to 2006. Ottawa: The Institute; 2007

2. Donaldson C, Shackley P. Economic evaluation. In: Detels R, Holland WW, McEwan J, et al, editors. Oxford textbook of public health. 3rd ed. Oxford: Oxford University Press; 1997. p. 849-70.

3. Canadian Agency for Drugs and Technologies in Health. CADTH presentation on the Common Drug Review to the House of Commons Standing Committee on Health. Ottawa: The Agency; 2007. Available: www.cadth.ca/media/media /CADTH_Submission_to_Standing_Committee_on_Health_070409.pdf (accessed 2007 Nov 22).

4. Kallah J. Formulary acceptance: monitoring and evaluation. Provincial Reimbursement Advisor 2006 Nov 9(4):57-77.

5. Morgan SG, McMahon M, Mitton C, et al. Centralized drug review processes in Australia, Canada, New Zealand, and the United Kingdom. Health Aff 2006;25:337-47

6. Manns B, Owen WF Jr, Winkelmayer WC, et al. Surrogate markers in clinical studies: Problems solved or created? Am J Kidney Dis 2006;48:159-66.

7. Fleming TR. Surrogate endpoints and the FDA's accelerated approval process. Health Aff (Millwood) 2005;24:67-78.

8. Biomarker Definitions Working Group. Biomarkers and surrogate endpoints: preferred definitions and conceptual framework. Clin Pharmacol Ther 2001;69:89-95.

9. Canadian Diabetes Association. The common drug review isn't working for Canadians with diabetes: written submission to the House of Commons Standing Committee on Health. Ottawa: The Association; 2007. Available: www.diabetes.ca |files/cdr-submission.pdf (accessed 2007 Nov 22).

Io. International Comparison of Canadian Expert Drug Advisory Committee (CEDAC) Common Drug Review (CDR) Recommendations. Ottawa: Canada's researchbased pharmaceutical companies; 2007. Available: www.canadapharma.org/Media /News/2006/I206-CDRInternationalComparison-FINALdraft-EN.pdf (accessed 2007 Nov 22).

Correspondence to: Dr. Braden Manns, Foothills Medical Centre, I403-29th St. NW; Calgary AB T2N 2T9; fax 403 944-2876; braden.manns@calgaryhealthregion.ca

Canadian Expert Drug Advisory Committee: Ken Bassett MD PhD, University of British Columbia; Bruce Carleton BPharm PharmD, University of British Columbia; John M. Conly MD, University of Calgary; Michael Evans MD, University of Toronto; Anne Holbrook MD PharmD, McMaster University; Laurie Mallery MD, Dalhousie University; Malcolm Man-Son-Hing MD MSc, University of Ottawa; Robert Peterson MD PhD, University of British Columbia; and Dale Quest PhD BSN, University of Saskatchewan. Public members: Nancy McColl BA BEd, Ottawa, Ont., and Brad Neubauer BA, Irvine, Alta. 